\title{
6
}

\section{Finding the Poster Child: Reference Patterns in OECD Country Reports}

\author{
Helen Seitzer
}

\section{Introduction ${ }^{1}$}

Universal compulsory education is a crucial aspect of today's welfare state legislation. With only a few exceptions, most countries around the world have at least implemented compulsory primary education (Chap. 2). However, this is not the only aspect of formalized schooling that most countries around the globe have in common. For quite some time now, researchers have observed an increasing similarity in education systems (Boli et al. 1985). A prominent theoretical approach used to explain this phenomenon is Meyer and colleagues' neo-institutionalist theory, which

\footnotetext{
${ }^{1}$ This chapter is a product of the research conducted in the Collaborative Research Center "Global Dynamics of Social Policy" at the University of Bremen. The center is funded by the Deutsche Forschungsgemeinschaft (DFG, German Research Foundation)_project number 374666841 SFB 1342.

H. Seitzer $(\bowtie)$

Collaborative Research Centre 1342 "Global Dynamics of Social Policy", University of Bremen, Bremen, Germany

e-mail: seitzer@uni-bremen.de

(C) The Author(s) 2022

K. Martens, M. Windzio (eds.), Global Pathways to Education, Global Dynamics of Social Policy, https://doi.org/10.1007/978-3-030-78885-8_6
} 
offers an explanation for globally shared institutional structures. The acceptance and adoption of standards and norms by major players in world society create pressure for other countries to implement these standards as well (Meyer et al. 1997). Nonetheless, the conditions of formalized schooling still differ between countries, for example, in terms of duration and modality (Chap. 3). Consequently, researchers have been not only asking how it is that education systems around the world have come to resemble each other but also where these features originated from, who is influencing this pool of standards, and which aspects of formalized schooling remain distinctive between countries (Meyer et al. 1997).

To answer the question, where the global standards established in education policy could come from, one has to ask who is influencing world society and driving the implementation of set global standards on a national level. One big influencing force is International Organizations (IOs). Interest groups like IOs, think tanks, and policy experts have increasingly gained influence in setting standards in world society and therefore on policy diffusion. Extensive data collection for evidencebased policymaking through International Large-Scale Assessments (ILSAs) along with policy advice in the form of policy reports have significantly simplified the process of identifying 'what works' in education and contributed to the perception of IOs, like the Organization for Economic Co-operation and Development (OECD), as 'knowledge brokers' of policymaking and drivers of policy diffusion (Niemann and Martens 2018). The comparison of education systems through the Programme for International Student Assessment (PISA) and country reports increases the use of references to foreign education system characteristics during policy development process in hopes of finding solutions to local problems in foreign education systems. In theory, this helps policymakers to identify 'best practice' models, place outcomes into perspective, and justify domestic reforms (Steiner-Khamsi 2014).

However, the OECD reports and policy recommendations are coined by a neo-institutional model of education inherent to the OECD, emphasizing aspects like school and regional autonomy, governing at a distance, and the implementation of global tests and standards. With this observation comes the concern of a one-size-fits-all distribution of a 
Western-rationalized education system that suppresses local influences and ignores local labor market needs (Zhao 2020). Despite the criticism that the OECD's overall approach to education is not only influenced by economic factors but also a Western-rationalist perspective, it is not entirely transparent which (Western-rationalized) education systems serve the OECD as reference models, or if there is such a thing as a single 'ideal model'. As a consequence of this lack of clarity, one could ask where exactly standards, policies, and the recommendations thereof come from; and how one country is informed of another country's education system, which might hold beneficial features. However, these questions are rarely asked in a comparative perspective but studied through country case studies.

In this chapter, I intend to close this gap and review the developmental trajectory of education policy recommendations in OECD publications. By analyzing the reference patterns within OECD country reports on education, I seek to understand if Western countries are indeed at the center of OECD policy recommendations and, if so, which countries are especially central. In addition, I seek to understand if there are specific education systems that are increasingly pushed toward a Western model, or if all countries are equally subject to that influence. Is the OECD strictly comparing Western and non-Western education systems, or is there a clear reference or recommendation path from only select Western countries toward the global periphery? Or if this not the case, are regional comparisons more common within the country reports?

To answer these questions, I will examine country reports on education by the OECD. Specifically, I will examine a network of country reports and the countries mentioned within them. This will display which countries are used as examples for policymaking in other countries' reports. First, I will assess visually if there are regional clusters detectable. Then, I will explore if there are more references within the clusters or between them. Therefore, establishing if the OECD has a region or country they perpetually use as an example for other countries. Furthermore, I will test the network statistically using an exponential random graph model. Consequently, the contribution of this chapter lies in the disaggregation of OECD references, detecting the most central education system, and regional reference patterns in OECD reports on education. 


\section{Ranking, Reporting, and Referencing}

As stated before, the isomorphism of institutions like formalized education is not surprising. The adherence of countries to world society standards has just as much to do with the social standing of these countries in world society as it does with improving their citizens' welfare (Ramirez et al. 2016).

The OECD can be regarded as the strongest driver of policy diffusion to date (Martens et al. 2014). The organization not only evaluates education systems through studies like PISA but also publishes a multitude of reports on different aspects of countries' education systems. The results of these studies and reports are often used to highlight 'best practices' to rank countries within league tables based on their performance but also to shame countries depending on their results (Tingley and Tomz 2019). These rankings are highly influential, as the strong reactions of some countries in the form of policy reforms indicate (Pons 2012).

Even before the commencement of PISA, the OECD published country reports, making policy recommendations based on their statistical analysis of the status quo. The targeted and effective publicity of these reports pressures countries to implement reforms according to the global standards, constituting the OECD's soft power (Addey 2017; Bieber 2016; Bieber and Martens 2011). Even though the reports assess withincountry aspects and are discussed among country delegates, they still heavily draw on the OECD's perspective. Centeno (2018), for example, states that the OECD secretariats have the decision-making power, as the reports are published under the secretariats' names (instead of the individual authors') and country delegates have to agree on the publications. But, since the OECD is officially working on behalf of the country officials, there tends to be minimal pushback, especially as country delegates perceive the OECD as working for them (Centeno 2018, 125). Not only does the OECD have a uniquely strong impact, but its headquarters are indeed located in western Europe. Statistically speaking, most of the scientists employed there might, more often than not, be born and trained somewhere in Europe or a country with similar academic traditions. This might cause a cultural bias, a phenomenon that can affect everyone. 
Therefore, the suspicion that the OECD is spreading a Western model of education is not unreasonable and this concern has only become more pronounced with the introduction of PISA and its reports (Zhao 2020). Aside from Hong Kong, Shanghai, South Korea, and Japan, the top performers of PISA are all located in Europe.

Another area of controversy regarding the OECD's policy recommendations concerns the perceived origin of ideas and standards as well as the strictness thereof. So far, research claims that the original 'model education system' was developed in Europe, in a Western society (Meyer et al. 1997; Anderson-Levitt 2003). Consequently, the outcomes, student achievement, and knowledge are tailored to prepare students for a Western-style capitalist labor market and society. While some countries are struggling to implement these standards, one of which is the participation in international large-scale assessments like PISA, it is said to unfairly benefit those countries whose education system is already built on these standards (Zhao 2020). In addition, the idea of education as a means to improve the workforce and thereby the national economy is a concept that originates in a capitalist, neoliberal society (Rutkowski 2007). The norms and values attached to this perspective on formalized education have an impact on the curriculum and the overall emphasis of formalized schooling in society (Steiner-Khamsi 2013; Anderson-Levitt 2003). The question here is whether these values apply to all cultures around the globe, or if there are other emphases that the education system should incorporate, especially in developing countries.

To identify these standards and norms, however, a certain level of comparison is necessary. In fact, comparison and references to foreign political systems has a long history. As Alasuutari et al. (2018) show in their study on British parliament debate records, referencing of foreign policies has been occurring since the 1800s. A more recent development is the notion of a 'model policy'. Early references simply state examples of foreign systems, while recent policy references in British parliament refer to specific policies, indicating the idea of a model or blueprint policy to learn from (Alasuutari et al. 2018). Luhmann's theory on self-referential systems offers an explanation for this phenomenon: He states that countries need to define themselves in demarcation to other countries, thereby creating a feedback system allowing them to redefine, experience, and 
rebuild their own identity. This, in turn, aids in implementing local regulations, which are distinct from the (national) 'other' (Luhmann 1990). His theory indicates that the comparison of education systems and their outcomes might be a more naturally occurring process than expected at first glance. This theory also accounts for a more local reference pattern instead of an overarching global model. However, the critical aspect regarding the dominating Western origin of policies and norms remains, especially if Western education systems are frequently referenced as examples.

References in an academic context usually refer to the citation of other academic works in a publication. In our context, however, it denotes the mention of a country in another country's report. These references are usually used as examples. This process allows us to trace potential influence: If one country is mentioned frequently or positively in another country's report, the probability of some kind of knowledge transfer increases. At the same time, by including a source for their recommendations and citing certain education systems as successes, the OECD's claims that certain reforms could improve a given education system are legitimized. References can, therefore, also be seen as a validation instrument (Steiner-Khamsi 2021). The references along with the publication of PISA results allow certain countries to gain a reputation as 'reference societies': countries whose education systems are regularly referenced as role models by other countries (Waldow et al. 2014; Adamson et al. 2017). These reference societies can change, as Silova (2006) observed: In post-Soviet states, Soviet references were removed and replaced with European references after the collapse of the Soviet Union, not only marking political changes but also the implied political orientation. Interestingly, this change only affected the discursive level and not the actual education system (Silova 2006). In addition, prejudice and culture play a significant role for reference societies: While some countries like Hong Kong and Shanghai are praised for their high PISA performance, they are rarely observed as reference societies. Teaching practices in Asia and the West are rumored to be significantly different, which in turn prevents these education systems from spreading, despite the excellent PISA scores (Waldow et al. 2014). 
As with global standards, a controversial issue that frequently resurfaces in this debate is the origin of these reference societies, since most are located in Europe (Schriewer and Matinez 2004; Silova 2006; SteinerKhamsi 2021). Even though single country reports and the use of external publications in national policymaking have been studied extensively (e.g. Baek et al. 2018; Adamson et al. 2017), the OECD's recommendations and references often remain vague and are rarely dissected and compared globally.

\section{The Influence of World Society}

As stated before, since education systems around the globe share certain characteristics such as classroom structures, curricula, and various administrative aspects like ministers, researchers have theorized as to how these commonalities came to be (Anderson-Levitt 2003, 5). The most commonly accepted theory of a shared world society describes a latent set of policy and norm development that is influenced by countries, IOs, and other actors. This implicit space of norms can be seen as an arena for policy diffusion: Countries legitimize themselves by adopting similar standards not only in education policy but also regarding broader concepts such as human rights and democracy (Meyer et al. 1997). This shared action allows for the dissemination of specific policies as well as ideas and understandings regarding education, its institutional structure, and its function within society. The implementation of global standards then increases interactions between countries and strengthens international relations due to seemingly shared ideologies. Very commonly, the standards adopted by world society originate in policy reports or papers regarding countries in the Global North. The OECD contributes greatly to the overall content of discussion in this space and therefore heavily influences the 'pool of accepted ideas' from which countries can choose education policy reforms. This creates homogeneity among countries that are part of world society. And while the OECD's reports are limited to countries commissioning them, world society is influencing all countries simultaneously. The OECD's recommendations, therefore, not only influence its member countries but also reach an increasing number of 
non-member states globally (Breakspear 2012). Important to note here is the agency countries have in this scenario but also the agency the OECD has in informing world society. The adoption of policies is action taken by countries alone but the distribution of information, which policies should be adopted, is the OECD's doing. The OECD influences world society standards by recommending specific aspects of education systems to many countries simultaneously, thereby increasing the diffusion of specific policies, creating a standardized education system around the globe.

On the other hand, education has traditionally been a local or national subject but is now heavily influenced at a global level (Sellar and Lingard 2014). In a traditional sense, education systems are initially derived from local, cultural contexts and are dependent on the local meaning of education, its tasks, and its functions within society. Although formalized schooling is already a form of standardization on the local level, global standards are much more critically debated. While some common institutional structures are observable (Anderson-Levitt 2003), some studies argue the acceptance of global standards is more of a political act and requires a level of universality, precision, and rationality that only few standards possess (Steiner-Khamsi 2013). Instead, countries implement standards only to a certain degree, retaining their cultural originality.

The debate on institutional isomorphism and the worldwide standardization of norms naturally leads to the question, how culture affects the expansion of standards and fosters or mediates the influence of world society. The definition of 'culture' and its influences on individual and institutional behavior are important but also controversial issues in social sciences (Anderson-Levitt 2012). While some approaches to cultural influences define rigid 'fault lines' separating cultural spaces and defining potential 'breaking points' (Huntington 1996), other approaches define culture as a set of common characteristics, such as religion, gender roles, language groups, and civil rights. The cultural spheres concept introduced in Chap. 2 defines culture as a valued two-mode network. If two countries share a cultural characteristic, they establish a link in a network. This approach allows for fuzzy boundaries, where ties between countries are stronger the more cultural characteristics they share. This network also allows for the definition of five cultural clusters, which will be included 
in the analysis further on. As discussed in Chap. 2, the exposure through this cultural network determines the introduction of compulsory education. To be more specific, the membership in certain cultural clusters, namely, Eastern European and WEIRD (western, educated, industrialized, resourceful, democratic) (Henrich 2020), increased the risk of introducing compulsory education.

Since formalized education is crucial for socialization and has developed over time in different ways depending on the local culture and history, it is also said to reproduce the culture of the origin country or region (Anderson-Levitt 2012). However, the standardization of education through the influence of IOs, like the OECD, fosters a narrow curriculum that only prepares students for a Western labor market and does not allow room for regional-specific education with regional-specific outcomes. This ultimately reproduces Western culture and homogenizes institutional forms as well as culture. Therefore, the standardization of education is often called Westernization or Americanization (Koh 2011; Alasuutari and Kangas 2020). Historically, political systems used to orient themselves toward historically or culturally similar countries (Bermeo 1992). This push toward a Western education system by instituting a 'global model' within world society undermines not only local influences but also local comparisons.

The question remaining is whether OECD references, seeing as they are pathways of influence, are restricted to a Western origin. Is the OECD undoubtedly favoring a Western model of education?

\section{Where to Look: Referencing in National Policymaking}

Several previous studies have investigated the origin of education policy reforms, mostly looking into single countries (e.g. Baek et al. 2018; Dobbins and Martens 2010). The data of various country reports supplied by the OECD provide excellent material for national policymakers to distinguish their national agenda from other nation-states — or to use them as an example for the reform implementation. It seems to be 
common practice for policymakers to consult experts before attempting to implement a reform, regardless if their advice was directly employed into policy action or not. This is naturally an excellent area for references between countries (Rautalin et al. 2018; Waldow et al. 2014).

Referencing foreign policies is not a phenomenon limited to education policy or the time after PISA, as discovered by Alasuutari and colleagues. British policy debates contain a relatively stable number of references to foreign systems, even historically (Alasuutari et al. 2018). Referencing and policy borrowing do not necessarily occur because reforms from elsewhere are better but because the very act of borrowing has a salutary effect on the relations between countries (Steiner-Khamsi 2006).

Finland, for example, served as a reference society after the first few PISA rounds, having achieved the highest performance out of all participants. Since then, Hong Kong and Shanghai have taken over that rule. However, despite the ranking, the choice of education systems as reference societies depends heavily on the interrelation of the respective nation-states and local traditions. Despite outstanding PISA scores, the Shanghai education system served as a negative reference point for several countries. The negative references are based on local culture- the (recent) European tradition of student-centered education stands in sharp contrast to Hong Kong's teacher-centered practice (Waldow et al. 2014). Nevertheless, Shanghai schools are praised for following the current performance standards of education.

Further studies found differential effects for referencing depending on the policy field and the subject in question. Furthermore, national references often seem to entail multiple countries depending on the policy context rather than just one, even though regional references often include blanket descriptors ('crisis-countries', 'well-off countries') (Pi Pi Ferrer et al. 2018). In addition to empirical evidence, both historical and cultural contexts seem to influence references as well (Sung and Lee 2017).

In general, references to other countries within policymaking processes seem to be quite common. The externalization of policy problems has become somewhat common in policy transfer research (Schriewer and Holmes 1990).

There are a few things to take away from studies on referencing in education policy: (1) The phenomenon is quite common in all policy 
fields and generally seen as a pipeline for influence between countries. It also affects academia, politics, and newspapers alike. (2) Countries are not the only ones that make references throughout policy documents. In fact, IOs are also considered influential in the creation of reference societies. While PISA certainly aided Finland and the Nordic countries in becoming reference societies, meaning they are the reference country for almost all other countries, PISA is not universally powerful. (3) Other aspects like cultural context play a role in the making of reference societies as well. What is missing in this research branch is the analysis of references within OECD documents. Even though not necessarily as powerful as the PISA results, other OECD published reports still bear great influence, as the OECD's 'best practice' models offer 'blueprints' for policy reform. The contribution of this chapter therefore lies in the disentanglement of OECD references, that is, in identifying the most central education systems or regional clustering in reference patterns within OECD reports.

\section{Data}

The data consist of 296 reports on countries' education systems that have been published through the OECD's publishing service between 1961 and 2019. The reports are published regularly on topics like Higher Education, Regional Development in regard to Education, Early Childhood Education and Care, and other aspects of formalized education. Reports are written by OECD staff in collaboration with experts on the subject within the country. Thus, as stated before, the content of these reports does not exclusively reflect either the OECD perspective or the perspective of country experts. However, studies were able to observe that the OECD does exercise strong control over the reports' contents (Centeno 2018).

The reports are reoccurring publications containing statistical and indepth analyses, discussing the status quo of a country's education system. They are organized in standardized series, discussing, for example, the status of the Early Childhood Education and Care system in place, Higher Education Management and Planning, Regional and City 
Development, or the overall reform efforts taken by countries in education since the last report. This tool provides policymakers with evidence for policymaking, showcases improvements, and makes recommendations on the grounds of other country reports or publications. Early reports often contained multiple countries in one publication, but the recent expansion and extensive data collection allow for 400 pages of figures and tables for each country almost every year.

To provide an example: In a report on Chile's education system in 2017 the OECD stated, "The centrally managed student allocation system in the Netherlands is another good option to keep in mind" (OECD 2017: 102), while discussing student allocation systems to different schools. Further on, they state that "[i]n the Netherlands, the Girls and Technology programme (Meisjes en Techniek) encourages girls to choose technical education and professions" (OECD 2017: 106), in a highlighted box along with more examples and citations to pinpoint options on how to close Chile's growing gender gap in science, technology, and math courses. These references are assumed to be always positive, unlike policymakers or scholars, the organization would severely damage their own reputation by highlighting negative examples. While there might be a bias toward OECD members, due to more information present, this is not a concern, as there are still reports by non-OECD members; similarly, non-OECD members are referenced to.

The publications in question were collected in 2019 from the OECD's online library ${ }^{2}$ and the OECD Archive in Paris. The final dataset consists of all country reports tagged with the label 'Education' by the OECD. A total of 296 country reports were published solely on education between 1961 and 2019. Sixty-five different countries commissioned country reports during that time. The documents were cleaned of tables and figures to avoid distorting the analysis.

A bibliographic analysis was performed, filtering the reports for references to other countries. Usually, bibliographical analyses on references means tracing the origin of other cited publications. Here, only mentions of country names are counted as references. These mentions allow us to trace which countries are most likely used as an example for which other

\footnotetext{
${ }^{2}$ https://www.oecd-ilibrary.org.
} 
World Regions according to Maddison (2010)

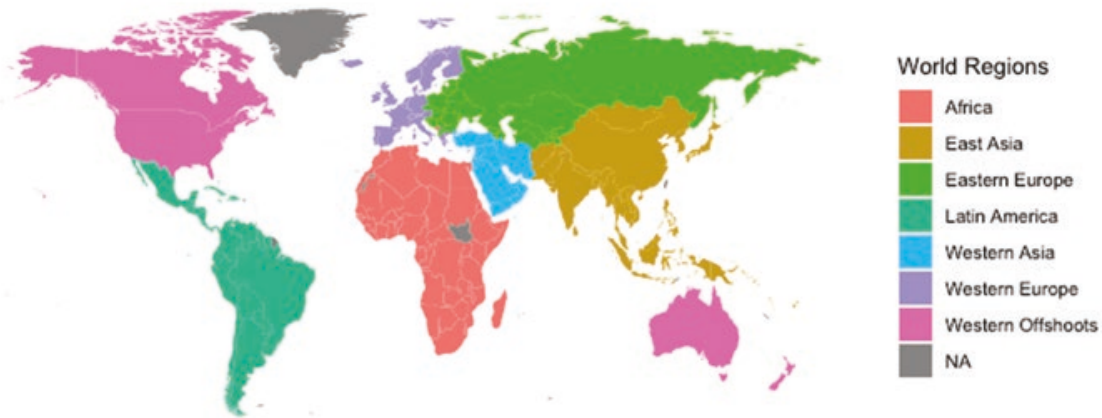

Fig. 6.1 Regional country groups according to Maddison

countries' report. This allows the building of a network between country reports and cited countries. This network includes a total of 129 countries, as some countries did not commission reports but were still cited. For the graphical analysis, self-references were removed as were all references below 10 mentions and above 200 mentions per country and per report, as they were suspected to be computation errors. The references were aggregated at the report level.

For further graphical analysis, the network was inspected after including the world regions developed by the Maddison Project (Fig. 6.1). ${ }^{3}$ Finally, an Exponential Random Graph Model (ERGM) for the regional groupings was implemented to show which countries were most often cited from outside their regional cluster and which clusters mostly cited other countries within the regional group.

\section{Results}

A total of 129 unique countries were referenced in the reports. The countries with the highest indegree-which means they were most frequently referenced-were Finland (a total of 1729 mentions), Germany (1685), Sweden (1407), and Australia (1300). Most references for Finland came

\footnotetext{
${ }^{3}$ http://www.ggdc.net/maddison/oriindex.htm.
} 
from Sweden, Norway, the United States, South Korea, and Japan. The country report with the most references of one specific country in a report was a report on Tajikistan, having referenced Kazakhstan a total of 381 times in one single report. The next most frequent references were from reports on Great Britain (specifically) mentioning England (291). The following three most frequent mentions were all from reports on the United States that referenced Singapore, Finland, and Germany. As one would expect, OECD countries that commission reports themselves are much more frequently referenced than countries that have not issued reports. This glimpse into the reference frequency hints toward an interesting development: There might be a regional reference pattern, as reports on Sweden and Norway often reference Finland, reports on Tajikistan references Kazakhstan, and reports on Great Britain discuss England specifically. ${ }^{4}$

Figure 6.2 shows the network with a stress majorization layout, placing the nodes with an optimal distance to each other: Nodes with many ties are placed in the middle, while isolated nodes are placed on the outside of the graph. The more ties that exist between two nodes, the closer together they are placed. This allows for a preliminary visual interpretation of possible reference patterns.

The network is a two-mode network: Country reports (circles) can only have outgoing ties and references (triangles) only have ingoing ties. The colors distinguish different regional clusters as described earlier. The tie strength signifies the frequency of a particular report referencing a particular country.

What is interesting to observe in this network is that there is a clear distinction between countries in the center, which are frequently referenced and those that are on the periphery of the graph. While Western European countries and Western Offshoots (Australia, Canada, New Zealand, and the USA) are frequently referenced and, therefore. at the center of the graph, African countries are not and are spread far out on the edges of the graph. Some of the Western Asian, Latin American, and

\footnotetext{
${ }^{4}$ Great Britain does not have one education system but several, depending on the political unit, therefore these regions were separated. It also demonstrates the OECD's priority of England over Wales or Scotland.
} 


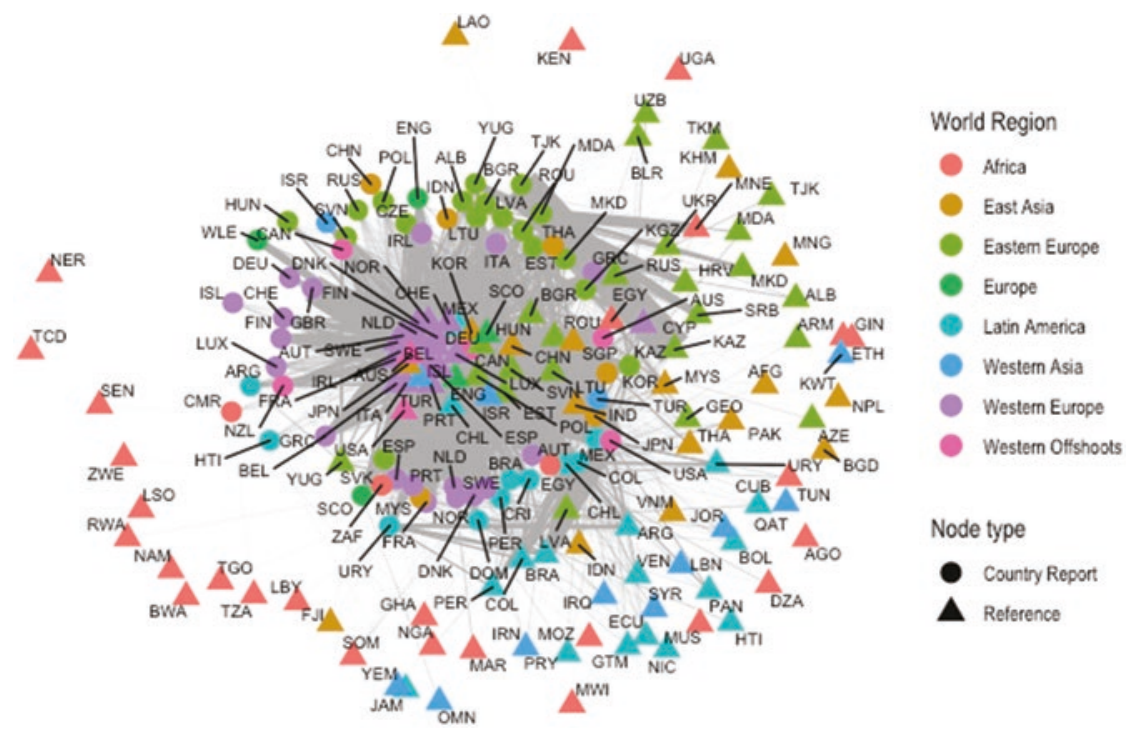

Fig. 6.2 Network of references

Eastern European or Asian countries are referenced often, while others are referenced much less. Their reference pattern is not as obvious. It seems as if the OECD does have a preference for referencing European countries relatively often. At the same time, there seems to be a geographical preference: Countries of the same region often cite reports of their neighbors, as the color pattern suggests. This indicates, at least within the OECD, regional references are equally as important as the reference to 'ideal cases', such as Singapore. But the fact that the references are not exclusively distributed within single clusters or to specific countries show that the suspected dissemination of a Western model might not be as strong as initially expected.

This observation is even more pronounced when only including reports published after the introduction of the PISA study in 2000. Even though Western European countries are in the center of the graph (see Fig. 6.3), just like before PISA's introduction, the regional clustering is more apparent. Especially the East Asian and Eastern European countries are often mentioned in reports from the same regional cluster. The countries with the most references after the year 2000 are Finland (949), Germany 


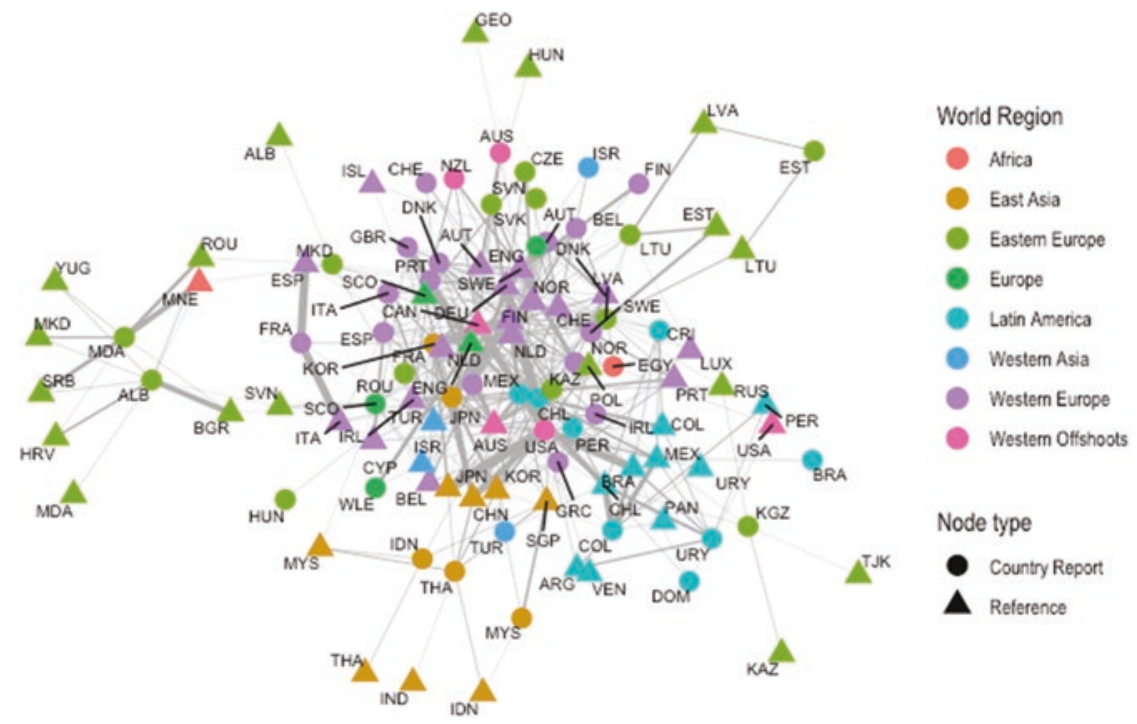

Fig. 6.3 Network of references after 2000

(798), Australia (742), and Canada (594). There seems to be favoritism toward European countries as reference points instead of toward PISA top performers. Germany, for example, did not score very high in the first PISA test round. Furthermore, despite being a top performer, Singapore was only referenced 226 times - a rather unexpected result. Chile, on the other hand, is referenced 482 times, despite consistently ranking below the OECD average. These results already indicate that the OECD does not have one single poster child but that there is not a general global model at play either.

To support this finding of unexpectedly frequent regional references with statistical results, Table 6.1 shows the results of a bipartite exponential random graph model (ERGM) that predicts the probability of tie formation between a report (network 1) and a country cited (network 2) in the network. In general, ERGMs allow the estimation of the likelihood of tie formation given all present ties in the network as well as node attributes. For example, it is possible to estimate the probability of citations of a country by a respective report, dependent on both countries' 
Table 6.1 ERGM model for homophily within regional and culture clusters

\begin{tabular}{|c|c|c|}
\hline & Model & \\
\hline & (1) & $(2)$ \\
\hline Edges & $-3.624^{* * *}$ & $-5.458^{* * *}$ \\
\hline b2factor East Asia & $0.450^{* * *}$ & $0.556^{\star * *}$ \\
\hline b2factor Eastern Europe & $0.077^{\star * *}$ & $-0.715^{\star \star *}$ \\
\hline b2factor Europe & $1.950^{\star \star *}$ & $1.715^{\star \star *}$ \\
\hline b2factor Latin America & $1.181^{\star * \star}$ & $0.527^{\star \star *}$ \\
\hline b2factor Western Asia & $0.590^{* * *}$ & $0.743^{* * *}$ \\
\hline b2factor Western Europe & 0.289 & $0.414^{* *}$ \\
\hline b2factor Western offshoots & 0.519 & -0.017 \\
\hline Nodemix OECD 0-1 & $3.692^{* * *}$ & $3.242^{\star \star *}$ \\
\hline Homophily OECD & $4.207^{* * *}$ & $3.862^{* * *}$ \\
\hline Homophily Africa & $0.197^{* * *}$ & $0.209^{* * *}$ \\
\hline Homophily East Asia & $0.270^{* * *}$ & $0.282^{* \star *}$ \\
\hline Homophily Eastern Europe & $0.207^{\star \star *}$ & $0.250^{\star * *}$ \\
\hline Homophily Europe & 0.645 & $0.880^{* *}$ \\
\hline Homophily Latin America & $0.169^{\star * *}$ & $0.220^{* * *}$ \\
\hline Homophily Western Asia & 0.389 & $0.345^{* * *}$ \\
\hline Homophily Western Europe & 0.247 & $0.233^{* * *}$ \\
\hline Homophily Western offshoots & -0.222 & $1.871^{\star \star \star}$ \\
\hline 2-star culture & & $0.522^{* * *}$ \\
\hline 3-star culture & & $-0.093^{* * *}$ \\
\hline 4-star culture & & $0.008^{* * *}$ \\
\hline Nodemix culture 1-1 & & $1.127^{\star * *}$ \\
\hline Nodemix culture $2-1$ & & $3.161^{\star * *}$ \\
\hline Nodemix culture 3-1 & & $2.854^{* * *}$ \\
\hline Nodemix culture 4-1 & & $3.208^{\star * *}$ \\
\hline Nodemix culture 5-1 & & $3.086^{* * *}$ \\
\hline Nodemix culture 1-2 & & $1.792^{\star \star *}$ \\
\hline Nodemix culture $2-2$ & & $2.054^{* * *}$ \\
\hline Nodemix culture $3-2$ & & $1.176^{* * *}$ \\
\hline Nodemix culture 4-2 & & $1.752^{* \star *}$ \\
\hline Nodemix culture 5-2 & & $1.807^{* * *}$ \\
\hline Nodemix culture 1-3 & & $1.902^{* * *}$ \\
\hline Nodemix culture $2-3$ & & $2.109^{* * *}$ \\
\hline Nodemix culture 3-3 & & $1.002^{* \star *}$ \\
\hline Nodemix culture $4-3$ & & $2.509^{\star \star \star}$ \\
\hline Nodemix culture $5-3$ & & $1.383^{\star \star *}$ \\
\hline Nodemix culture 1-4 & & $1.636^{* * *}$ \\
\hline Nodemix culture 2-4 & & $0.893^{* * *}$ \\
\hline Nodemix culture 3-4 & & $1.172^{\star * *}$ \\
\hline
\end{tabular}


Table 6.1 (continued)

\begin{tabular}{lll}
\hline & Model & \\
\hline & $(1)$ & $(2)$ \\
\hline Nodemix culture 4-4 & & 0.983 \\
Nodemix culture 5-4 & & 1.768 \\
Akaike Inf. Crit. & 6270.791 & 5716.667 \\
Bayesian Inf. Crit & 6395.675 & 6001.125 \\
\hline
\end{tabular}

Note: ${ }^{*} p<0.1 ;{ }^{* *} p<0.05 ;{ }^{* * *} p<0.01$

(referencing and cited) membership status in the OECD. This shows if non-OECD members are more likely to be informed of OECD members' education system practices than other non-OECD members.

The coefficients are untransformed; they therefore represent the log odds of tie formation. In the present model, I included the Maddison's World Regions as described above, to estimate the likelihood of being cited given a countries' geographical location. Then, I estimate the impact of OECD and non-OECD membership on referencing and finally include five cultural clusters, derived from the 'cultural spheres' network from 1962 described in Chap. 2. Cluster 1 of the cultural spheres comprises mostly WEIRD countries, ${ }^{5}$ cluster 2 Spanish-Catholic 6 countries, cluster 3 Eastern European ${ }^{7}$ countries, and cluster 4 Predominantly Muslim ${ }^{8}$ countries while cluster 5 includes mostly African, not predominantly Muslim ${ }^{9}$ countries. The second model shows a slightly

\footnotetext{
${ }^{5}$ 1: WEIRD: Australia, Austria, Belgium, Bangladesh, Canada, Switzerland, Germany, Denmark, England, Finland, Fiji, France, United Kingdom, India, Ireland, Iceland, Israel, Italy, Jamaica, Japan, Luxembourg, Mauritius, Nigeria, Netherlands, Norway, New Zealand, Scotland, Singapore, Sweden, United States, Wales.

${ }^{6}$ 2: Spanish-Catholic: Argentina, Bolivia, Brazil, Chile, Colombia, Costa Rica, Cuba, Dominican Republic, Ecuador, Spain, Guatemala, Mexico, Nicaragua, Panama, Peru, Portugal, Paraguay, Uruguay, Venezuela.

73: Eastern European: Armenia, Azerbaijan, Bulgaria, Belarus, China, Cyprus, Czechia, Estonia, Georgia, Greece, Croatia, Haiti, Hungary, Kazakhstan, Kyrgyzstan, Lithuania, Latvia, Moldova, North Macedonia, Montenegro, Mongolia, Poland, Romania, Russia, Serbia, Slovakia, Slovenia, Thailand, Tajikistan, Turkmenistan, Ukraine, Uzbekistan, Vietnam, Yugoslavia.

${ }^{8}$ 4: Predominantly Muslim: Afghanistan, Albania, Algeria, Egypt, Ethiopia, Guinea, Indonesia, Iran, Iraq, Jordan, Cambodia, South Korea, Kuwait, Lebanon, Libya, Morocco, Malaysia, Niger, Nepal, Oman, Pakistan, Qatar, Senegal, Somalia, Syria, Chad, Tunisia, Turkey, Yemen.

95: African, not predominantly Muslim: Angola, Botswana, Cameroon, Ghana, Kenya, Laos, Lesotho, Mozambique, Malawi, Namibia, Rwanda, Togo, Tanzania, Uganda, South Africa, Zimbabwe.
} 
better model fit, controlling for culture clusters seems to enhance the model fit and provide more information than only controlling for geographical region.

The first effect of the model (edge) simply describes the log odds of tie formation. The following b2factor effects of the table describe the log odds of being referenced, based on the network attribute (here the World Regions, as described earlier) in contrast to the reference category Africa. All effects are positive, except for Eastern Europe in model 2, with countries from Europe showing the highest coefficients. European countries are referenced more often than countries from all other regions, making it somewhat a 'reference-region'. Latin America has a surprisingly large coefficient in model 1 as well. However, there seems to be a cultural component: When including controlling for the culture cluster as seen in model 2, the effect of being located in Latin America on the frequency of being cited reduces. This indicates that the culture, or belonging to a specific culture cluster influences the citation frequency as well.

Nodemix terms describe the log odds of a tie between a report and a referenced country based on the given node attributes. OECD members are coded with 1 , non-members with 0 . As expected, there are more reports on non-OECD member countries citing OECD member countries more often, since there are more reports on OECD-members then there are reports on non-OECD-Members.

The differential homophily effect describes the log odds of ties from a report to a reference country, if both countries have the same attribute level. The homophily effect for (only) OECD countries confirms the assumption that OECD countries are being used as reference countries more often than non-member states.

For all World Regions, the differential homophily effect is surprisingly small but positive. Consequently, there is a tendency for citations to countries within the same World Region as the country of the report. These effects are larger for Europe, Western Asia, but especially Western Offshoots in model 2 compared to the other regions, illustrating that reference countries are more likely to be within the same World Region as the country that is receiving the recommendation.

The in-star effects describe the log odds of having between two and four incoming ties from the same culture cluster. The log odds of two incoming ties from the same culture cluster are positive, describing a 
greater probability of two incoming ties from the same culture cluster than from other culture clusters. The three in-stars effect is negative, meaning there are less chances of three references forming the same culture cluster. Overall, the effects are relatively small.

The last effects describe the log odds of ties between reports and references from the denoted culture cluster. Here it is especially interesting, how the overall effect sizes are distributed. Citations to countries in cluster 5 are the reference category here. References to countries in culture cluster 1 (WEIRD) are generally relatively prevalent, the effects are significant, positive, and relatively large. Especially in reports from cluster 2, cluster 4, and cluster 5 (Spanish-Catholic, Predominantly Muslim: Turkey, Egypt, Albania, but also South Korea and African, non-Muslim countries). Cluster 2, Spanish-Catholic countries, tends to be cited from reports on countries in the same cluster most often than from reports on countries in other clusters. Cluster 3, Easter European, hosts popular reference countries as well, especially from cluster 2 and cluster 4 .

These results are in line with the earlier results, showing that there is a tendency for referencing within the same cultural as well as geographical region. In addition, there is a strong preference for references to WEIRD or European countries.

In summary, first, the regional pattern from Fig. 6.2 seems to express positive homophily effects for World Regions, there is a tendency for references within the same region-especially for the Western Offshoots but also for Europe and Western Asia. Second, European countries are the most referenced. Additionally, OECD countries are referenced more than non-member states. Third, culture seems to matter in these reference patterns. Cluster 2, WEIRD, and cluster 3 Eastern Europe are referenced the most in reports from other culture clusters. Cluster 2, Spanish-Catholic, has the highest effect for within-cluster citations. Some cultural and geographical regions are, therefore, more prone to receive recommendations based on the countries' culture and location, while others receive recommendations in line with a 'global model' without the preference for regional examples.

Therefore, one cannot assume the OECD has one 'model education system' or one poster-child after which all recommendations are modeled; instead, there seems to be an awareness within the organization that 
countries are suitable as reference societies to the countries receiving the recommendation. Despite general perceptions, it is safe to say there is no 'one global model' of an education system. However, there is a preference for countries mostly located in Europe, warranting the criticism of scholars that the OECD is driving toward a 'western European' model of education.

\section{Conclusion}

In this chapter, I analyzed OECD country reports on education against the backdrop of the criticism that the OECD fosters and spreads a Western model of education. European countries are used as examples for system structures elsewhere in the world. The results indicate a higher frequency of references to European countries as opposed to nonEuropean countries. However, it must be taken into account that OECD member countries are mostly located in Europe, and a higher number of reports are accordingly commissioned by these countries. Nevertheless, there is a surprisingly unclear pattern of references. To gain a better understanding of the rather confusing pattern, regional clusters were included and later cultural clusters. This revealed an increased preference for regional references in addition to a high number of references to European countries, though mainly Finland and Germany. The Westernization of education is just as much a Finlandization, a Europeanization, or even a 'localization' of education policy. Referencing geographically close countries seems to be just as important as referencing the best performing systems, such as Finland. However, Finland's success with PISA might be easily referenced as an example without clear indication what aspects of the Finnish education system are to be used. Instead, this could be a projection for success of an education system, making the reference to Finland more a reference to success than to a specific education system characteristic.

While the reference patterns have no clear central nodes, there are indeed 'favorites': European OECD-members. This is not surprising, as there may be more information available, but it warrants the warning that the OECDs' recommendations are leaning toward a Western, 
European model of education. Interesting to note is the referencing preference between the regions: Some regions such as Europe, Western Asia, and the Western Offshoots seem to prefer references to regionally close countries, while others such as Latin America or Eastern Asia do not. Culture seems to matter within this pattern as well. Aside from the preference for the countries in the WEIRD cluster, it is less clear which countries are most referenced. These results confirm Western or European countries are referenced the most from their own geographical or cultural region as well as from other countries.

While there are similar institutional structures of education systems around the world, the results of this study imply that these standards and norms might travel differently than the way often portrayed. The standardization of education, even though 'Western-oriented', is much more dependent on the geographical closeness of countries. When studying the path of education policy diffusion, new insights might arise in the context of geographically, religiously, linguistically, or ethnically similar countries as well as those that are historically tied to one another. The diffusion chain of policy borrowing but especially of referencing might be much shorter than expected. In addition, this observation supports the idea of externalization in the sense of Luhmann's self-referential systems (Luhmann 1990) as opposed to the acceptance of a global model in world society's terms (Meyer et al. 1997). PISA might be a global comparison of decontextualized student achievement but the comparison of actual policies by the OECD might be much more oriented toward closely related countries. Especially upon closer inspection of the first graph on references, it seems more intuitive that geographically close countries are tied more closely, as most of them share similar institutional and cultural traits. Externalizations in the form of references between those countries are therefore much easier to understand. And while Finland is without a doubt the OECD's poster child, given that it holds the highest number of references across all time, it is not the only country with a consistently high number of references. Since the homogenization of education systems is not a latent idea but rather reality, a common model is still being circulated, though it might be diffusing along different pathways than initially anticipated. To understand the regionally dependent preference for regional citations, even in reports published by a transnational 
organization, it might be worth including more factors into the analysis such as openness or cultural traits.

Furthermore, it might be important for upcoming research on the diffusion of education policy, but also on the OECD, to consider regional influences instead of focusing solely on global influences of the OECD. In addition, inspecting reference societies not through the OECD's lens but through country reports or policy papers from other sources might reveal different results. It is also worthy to note, that the overall notion of the OECD's influence on a global model of education is not as strong as expected. The regional recommendation pattern from the OECD warrants a closer look into the diffusion of policies, as this might provide insights into the pathways of these policies instead of assuming a global influence through a world society.

\section{References}

Adamson, Bob, Katherine Forestier, Paul Morris, and Christine Han. 2017. PISA, Policymaking and Political Pantomime: Education Policy Referencing between England and Hong Kong. Comparative Education 53 (2): 192-208. https://doi.org/10.1080/03050068.2017.1294666.

Addey, Camilla. 2017. Golden Relics \& Historical Standards: How the OECD Is Expanding Global Education Governance through PISA for Development. Critical Studies in Education 58 (3): 311-325. https://doi.org/10.108 0/17508487.2017.1352006.

Alasuutari, Pertti, and Anita Kangas. 2020. The Global Spread of the Concept of Cultural Policy. Poetics. https://doi.org/10.1016/j.poetic.2020.101445.

Alasuutari, Pertti, Marjaana Rautalin, and Jukka Tyrkkö. 2018. The Rise of the Idea of Model Policymaking: The Case of the British Parliament, 1803-2005. European Journal of Sociology 59 (3): 341-363. https://doi.org/10.1017/ S0003975618000164.

Anderson-Levitt, Kathryn M. 2003. A World Culture of Schooling? In Local Meanings, Global Schooling: Anthropology and World Culture Theory, ed. Kathryn M. Anderson-Levitt, 1-41. New York: Palgrave Macmillan. https:// doi.org/10.1057/9781403980359_1.

. 2012. Complicating the Concept of Culture. Comparative Education 48 (4): 441-454. https://doi.org/10.1080/03050068.2011.634285. 
Baek, Chanwoong, Bernadette Hörmann, Berit Karseth, Oren Pizmony-Levy, Kirsten Sivesind, and Gita Steiner-Khamsi. 2018. Policy Learning in Norwegian School Reform: A Social Network Analysis of the 2020 Incremental Reform. Nordic Journal of Studies in Educational Policy 4 (1): 24-37. https://doi.org/10.1080/20020317.2017.1412747.

Bermeo, Nancy. 1992. Democracy and the Lessons of Dictatorship. Comparative Politics 24 (3): 273-291. https://doi.org/10.2307/422133.

Bieber, Tonia. 2016. Soft Governance, Organizations and Education Policy Convergence Comparing PISA and the Bologna and Copenhagen Processes. Baskingstoke: Palgrave Macmillan.

Bieber, Tonia, and Kerstin Martens. 2011. The OECD PISA Study as a Soft Power in Education? Lessons from Switzerland and the US. European Journal of Education 46 (1): 101-116. https://doi.org/10.1111/j.14653435.2010.01462.x.

Boli, John, Francisco O. Ramirez, and John W. Meyer. 1985. Explaining the Origins and Expansion of Mass Education. Comparative Education Review 29 (2): 145-170. https://doi.org/10.1086/446504.

Breakspear, Simon. 2012. The Policy Impact of PISA: An Exploration of the Normative Effects of International Benchmarking in School System Performance. 71. OECD Education Working Papers. Paris: OECD Publishing. https:// doi.org/10.1787/5k9fdffffr28-en.

Centeno, Vera G. 2018. The OECD's Educational Agendas-Framed from Above, Fed from Below, Determined in Interaction. Bern, Schweiz: Interactive Factory. https://doi.org/10.3726/b12774.

Dobbins, Michael, and Kerstin Martens. 2010. Towards an Education Approach à La Finlandaise? French Education Policy after PISA. Studies in Health Technology and Informatics 155: 163-169. https://doi.org/10.1080/0268093 9.2011.622413.

Henrich, Joseph. 2020. The Weirdest People in the World: How the West Became Psychologically Peculiar and Particularly Prosperous. Farrar, Straus and Giroux. Huntington, Samuel P. 1996. The Clash of Civilizations and the Remaking of World Order. New York: Simon \& Schuster.

Koh, Aaron. 2011. Singapore's 'Global Assemblage': Digging into the Culture of Education Policy Making. Critical Studies in Education 52 (3): 267-278. https://doi.org/10.1080/17508487.2011.604076.

Luhmann, Niklas. 1990. Essays on Self-Reference. New York, NY: Columbia University Press.

Martens, Kerstin, Philipp Knodel, and Michael Windzio, eds. 2014. Internationalization of Education Policy. A New Constellation of Statehood in 
Education? Basingstoke: Palgrave Macmillan. https://doi. org/10.1108/10867371011048643.

Meyer, John W., John Boli, George M. Thomas, and Francisco O. Ramirez. 1997. World Society and the Nation-State. American Journal of Sociology 103 (1): 144-181. https://doi.org/10.1086/231174.

Niemann, Dennis, and Kerstin Martens. 2018. Soft Governance by Hard Fact? The OECD as a Knowledge Broker in Global Education Policy. Global Social Policy 18 (3): 267-283. https://doi.org/10.1177/1468018118794076.

OECD. 2017. Education in Chile. Reviews of National Policies for Education. Paris: OECD Publishing. https://doi.org/10.1080/03064227708532690.

Pi Ferrer, Laia, Pertti Alasuutari, and Leena Tervonen-Gonçalves. 2018. Looking at Others in National Policy-Making: The Construction of Reference Groups in Portugal and Spain from 2008 to 2013. European Politics and Society 20 (3): 333-347. https://doi.org/10.1080/23745118.2018.1540157.

Pons, Xavier. 2012. Going beyond the 'PISA Shock' Discourse: An Analysis of the Cognitive Reception of PISA in Six European Countries, 2001-2008. European Educational Research Journal 11 (2): 206-226. https://doi. org/10.2304/eerj.2012.11.2.206.

Ramirez, Francisco O., John W. Meyer, and Julia Lerch. 2016. World Society and the Globalization of Educational Policy. In The Handbook of Global Education Policy, ed. Karen Mundy, Andy Green, Bob Lingard, and Antoni Verger, 43-63. Ltd: John Wiley \& Sons. https://doi. org/10.1002/9781118468005.ch2.

Rautalin, Marjaana, Pertti Alasuutari, and Eetu Vento. 2018. Globalisation of Education Policies: Does PISA Have an Effect? Journal of Education Policy 34 (4): 500-522. https://doi.org/10.1080/02680939.2018.1462890.

Rutkowski, David J. 2007. Converging Us Softly: How Intergovernmental Organizations Promote Neoliberal Educational Policy. Critical Studies in Education 48 (2): 229-247. https://doi.org/10.1080/17508480701494259. Schriewer, Jürgen, and Brian Holmes. 1990. Theories and Methods in Comparative Education. Bern, Schweiz: Peter Lang.

Schriewer, Jürgen, and Carlos Matinez. 2004. Construction of Internationality in Education. In The Global Politics of Educational Borrowing and Lending, ed. Gita Steiner-Khamsi, 29-53. New York: Teachers College Press.

Sellar, Sam, and Bob Lingard. 2014. The OECD and the Expansion of PISA: New Global Modes of Governance in Education. British Educational Research Journal 40 (6): 917-936. https://doi.org/10.1002/berj.3120. 
Silova, Iveta. 2006. From Sites of Occupation to Symbols of Multiculturalism: Re-Conceptualizing Minority Education in Post-Soviet Latvia. Greenwich: Information Age Publishing.

Steiner-Khamsi, Gita. 2006. The Economics of Policy Borrowing and Lending: A Study of Late Adopters. Oxford Review of Education 32 (5): 665-678. https://doi.org/10.1080/03054980600976353.

— 2013. What Is Wrong with the 'What-Went-Right' Approach in Educational Policy? European Educational Research Journal 12 (1): 20-33. https://doi.org/10.2304/eerj.2013.12.1.20.

- 2014. Cross-National Policy Borrowing: Understanding Reception and Translation. Asia Pacific Journal of Education. Taylor \& Francis. https:// doi.org/10.1080/02188791.2013.875649.

2021. What Is a Reference? Theoretically Understanding the Uses of Evidence in Education Policy. In Evidence and Expertise in Nordic Education Policies: A Comparative Network Analysis from the Nordic Region, ed. Berit Kaseth, Kirsten Sivesind, and Gita Steiner-Khamsi. Cham: Palgrave Macmillan.

Sung, Youl Kwan, and Yoonmi Lee. 2017. Is the United States Losing Its Status as a Reference Point for Educational Policy in the Age of Global Comparison? The Case of South Korea. Oxford Review of Education 43 (2): 162-179. https://doi.org/10.1080/03054985.2016.1257424.

Tingley, Dustin, and Michael Tomz. 2019. The Effects of Naming and Shaming on Public Support for Compliance with International Agreements: An Experimental Analysis of the Paris Agreement 1. https://scholar.harvard.edu/ dtingley/publications/effects-naming-and-shaming-public-supportcompliancewith-international.

Waldow, Florian, Keita Takayama, and Youl Kwan Sung. 2014. Rethinking the Pattern of External Policy Referencing: Media Discourses over the Asian Tigers' PISA Success in Australia, Germany and South Korea. Comparative Education 50 (3): 302-321. https://doi.org/10.1080/0305006 8.2013.860704.

Zhao, Yong. 2020. Two Decades of Havoc: A Synthesis of Criticism against PISA. Journal of Educational Change 21 (2): 245-266. https://doi. org/10.1007/s10833-019-09367-x. 
Open Access This chapter is licensed under the terms of the Creative Commons Attribution 4.0 International License (http://creativecommons.org/licenses/ by/4.0/), which permits use, sharing, adaptation, distribution and reproduction in any medium or format, as long as you give appropriate credit to the original author(s) and the source, provide a link to the Creative Commons licence and indicate if changes were made.

The images or other third party material in this chapter are included in the chapter's Creative Commons licence, unless indicated otherwise in a credit line to the material. If material is not included in the chapter's Creative Commons licence and your intended use is not permitted by statutory regulation or exceeds the permitted use, you will need to obtain permission directly from the copyright holder.

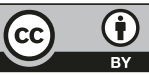

